\title{
Misuse of drugs and personalized treatment in geriatric patients
}

\author{
Ramon Cacabelos \\ Institute of Medical Science and Genomic Medicine, EuroEspes Biomedical Research Center, Spain
}

*Correspondence to: Ramón Cacabelos, Institute of Medical Science and Genomic Medicine, EuroEspes Biomedical Research Center, 15165-Bergondo, Corunna, Spain

Received: September 25, 2017; Accepted: October 02, 2017; Published: October 02, 2017;

\section{Editorial}

Many voices from different sectors of the medical and scientific community have been warning us for decades about the disastrous consequences of the misuse and abuse of certain pharmacological treatments in medical practice. This is particularly alarming in the case of geriatric patients. Cardiovascular disorders, cancer and brain disorders are the principal causes of death and disability in developed societies. All these medical conditions are age-related, with increased prevalence and incidence in parallel with aging. Furthermore, the costs attributed to pharmacological treatment in these pathologies represent about $10-20 \%$ of the direct cost of disease, depending upon the country. Among brain disorders, neuropsychiatric disorders (psychotic syndromes, major depression, bipolar disorder, anxiety, sleep disorders, epilepsy, chronic pain, migraine), neurodegenerative disorders (Alzheimer's disease, Parkinson's disease) and stroke account for approximately $80 \%$ of the outlay in chronic pharmacological treatments. Additionally, only $20-30 \%$ of the drugs administered for the treatment of chronic disorders of the central nervous system are cost-effective, and most of them are not devoid of adverse drug reactions (ADRs). In this context, the medical community, the pharmaceutical industry and the regulatory agencies (FDA, EMA, Koseisho) should revise current treatment protocols and decisionmaking strategies to reverse this unacceptable situation.

The elderly population with chronic disorders may consume 6-10 different drugs per day with the consequent risk of drug-drug interactions (DDIs). Approximately $10-20 \%$ of prescriptions in the general population are susceptible to DDIs [1-3]. Especially dangerous is the association of anticoagulants (warfarin) and non-steroidal antiinflammatory drugs (NSAIDs) [2,4,5]. In elderly patients, DDIs are prevalent in the USA and Europe with a frequency ranging from $12 \%$ to $40 \%[6,7]$. Preventable ADR rates in ambulatory care surpass $15 \%$ and in hospital care reach $50-75 \%$ [8]. In patients with DDIs, the median DDI prevalence for hospital admissions ranges from $4 \%$ to $20 \%[9,10]$. Incorrect prescription of NSAIDs is the most frequent cause of hospital admission [9], together with inappropriate medications for cardiovascular disorders in adults and elderly patients $[2,11]$. In geriatric patients, the most frequent symptoms that require hospitalization include gastrointestinal complaints and metabolic and hemorrhagic complications associated with the misuse of diuretics, calcium channel blockers, NSAIDs and digoxin [12,13]. In these cases, the most important determinant of risk for ADR-related hospital admissions is the number of inappropriate drugs prescribed to the patients, and self-medication [12-15]. Cardiovascular drugs, analgesics, and hypoglycemic agents account for over $85 \%$ of preventable ADRs in ambulatory care, and about $77 \%$ of these preventable ADRs result in CNS symptoms [16]. The rate of preventable ADRs in intensive care units is about 19 events per 1000 patient days, and almost twice that rate in non-intensive care facilities [17]. It has also been reported that admissions caused by preventable ADRs represent an additional cost of $\$ 6685$ per event [18].

These figures have been passively accepted by the medical community and health authorities for decades, and no apparent reduction in ADR- or DDI-related events has been observed in recent times, despite spectacular progress in medical technologies and management procedures. Accidental risks in medical practice are unavoidable in many instances, especially in fragile patients with chronic and/or terminal diseases. However, nowadays, the incorporation of predictive biomarkers and pharmacogenetic procedures may help health professionals to improve the efficacy and safety of pharmacological treatments in both ambulatory and hospital settings [19-26].

There is a clear parallelism between the efficacy and safety of drugs and the pharmacogenetic profile of patients. It is estimated that only one-third of drugs are cost-effective and only $20 \%$ of the Caucasian population is extensive metabolizer for the gene cluster integrated by major polymorphic variants of the CYP2D6-CYP2C9-CYP2C19CYP3A4/5 genes (involved in the metabolism of $60-80 \%$ of current drugs worldwide) [19,27-30]. According to these estimations, it is likely that the administration of a drug at random, by trial-and-error, following conventional protocols, will result in a lack of effect or in toxicity, assuming that $80 \%$ of the population is intermediate, poor or rapid metabolizer for phase-I reaction enzymes encoded by CYP genes [30].

Pharmacogenetics accounts for a $60-80 \%$ variation in drug pharmacokinetics and pharmacodynamics. The genes involved in the pharmacogenetic cascade include (i) pathogenic genes associated with the etiology and pathogenesis of a given disease, (ii) mechanistic genes associated with the mechanism of action of drugs, (iii) metabolic genes encoding phase-I and phase-II enzymes responsible for the metabolism of drugs, (iv) transporter genes that encode transporter proteins; and (v) and pleiotropic genes involved in multiple metabolomic cascades $[29,30]$. The expression of all these genes is under the control of the epigenetic machinery (DNA methylation, chromatin/histone modifications, microRNA regulation) [31]. The 
normal functioning of this complex apparatus is essential for the optimization of therapeutics, and genomic and/or epigenetic defects in this regulatory network are responsible for drug efficacy and safety, and drug resistance as well [32].

At present, the implementation of pharmacogenetic procedures in clinical practice is the only effective way to optimize therapeutics, to reduce ADRs and DDIs, and to eliminate unnecessary costs associated with ADR/DDI events. However, pharmacogenetics is still an immature discipline, with a need for substantial improvement in specificity and sensitivity. The World Guide for Drug Use and Pharmacogenomics [19] provides basic information on the pharmacogenetics of over 1000 FDA-approved drugs, and some other excellent sources from the academia and public and private websites [33,34] are contributing to educate physicians and scientists on the utility of pharmacogenomics in drug prescription and drug development.

Despite the documented benefits provided by pharmacogenetics, there is still reluctance in the medical community and administration to incorporate pharmacogenetics into current therapeutic protocols. The rejection of novelty is a typical behavior of the human species. However, in any case, a personalized treatment, based on pharmacogenetic principles, will always be better than the personal preferences or the intuition of the medical prescriber, and naturally much more honest and accurate than the guidelines dictated by the pressure of industrial marketing.

\section{References}

1. Jazbar J, Locatelli I, Horvat N, Kos M (2017) Clinically relevant potential drugdrug interactions among outpatients: A nationwide database study. Res Social Adm Pharm S1551: 30041-30044. [crossref]

2. Toivo TM, Mikkola JA, Laine K, Airaksinen M (2016) Identifying high risk medications causing potential drug-drug interactions in outpatients: A prescription database study based on an online surveillance system. Res Social Adm Pharm 12: 559-568. [crossref]

3. Kongkaew C, Noyce PR, Ashcroft DM (2008) Hospital admissions associated with adverse drug reactions: a systemic review of prospective observational studies. Ann Pharmacother 42: 1017-1025. [crossref]

4. Gagne JJ, Maio V, Rabinowitz C (2008) Prevalence and predictors of potential drug-drug interactions in Regione Emilia-Romagna, Italy. J Clin Pharm Ther 33: 141-151. [crossref]

5. Maio V, Yuen EJ, Novielli K, Smith KD, Louis DZ (2006) Potentially inappropriate medication prescribing for elderly outpatients in Emilia Romagna, Italy: a population-based cohort study. Drugs Aging 23: 915-924. [crossref]

6. Gallagher P, Barry P, O’Mahony D (2007) Inappropriate prescribing in the elderly. $J$ Clin Pharm Ther 32: 113-121. [crossref]

7. Liu GG, Christensen DB (2002) The continuing challenge of inappropriate prescribing in the elderly: an update of the evidence. J Am Pharm Assoc (Wash) 42: 847-857. [crossref]

8. Taché SV, Sönnichsen A, Ashcroft DM (2011) Prevalence of adverse drug events in ambulatory care: a systematic review. Ann Pharmacother 45: 977-989. [crossref]

9. Dechanont S, Maphanta S, Butthum B, Kongkaew C (2014) Hospital admissions/ visits associated with drug-drug interactions: a systematic review and metaanalysis. Pharmacoepidemiol Drug Sat 23: 489-497. [crossref]

10. von Laue NC, Schwappach DL, Koeck CM (2003) The epidemiology of preventable adverse drug events: a review of the literature. Wien Klin Wochenschr 115: 407415. [crossref]

11. Kanjanarat P, Winterstein AG, Johns TE, Hatton RC, Gonzalez-Rothi R, et al. (2003) Nature of preventable adverse drug events in hospitals: a literature review. Am J Health Syst Pharm 60: 1750-1759. [crossref]

12. Onder G, Pedone C, Landi F, Cesari M, Della Vedona C, et al. (2001) Adverse drug reactions as cause of hospital admissions: results from the Italian Group of
Pharmacoepidemiology in the Elderly (GIFA). J Am Geriatr Soc 50: 1962-1968. [crossref]

13. Passarelli MC, Jacob-Filho W, Figueras A (2005) Adverse drug reactions in an elderly hospitalized population: inappropriate prescription is a leading cause. Drugs Aging 22: 767-777. [crossref]

14. Olivier P, Bertrand L, Tubery M, Lauque D, Montastruc JL, et al. (2009) Hospitalizations because of adverse drug reactions in elderly patients admitted through the emergency department: a prospective survey. Drugs Aging 26: 475482. [crossref]

15. Wright A, Flebowitz J, Phansalkar S, Liu J, Wilcox A, et al. (2012) Preventability of adverse drug events involving multiple drugs using publicly available clinical decision support tools. Am J Health Syst Pharm 69: 221-227. [crossref]

16. Thomsen LA, Winterstein AG, Søndergaard B, Haugbølle LS, Melander A (2007) Systematic review of the incidence and characteristics of preventable adverse drug events in ambulatory care. Ann Pharmacother 41: 1411-1426. [crossref]

17. Cullen DJ, Sweitzer BJ, Bates DW, Burdick E, Edmondson A, et al. (1997) Preventable adverse drug events in hospitalized patients: a comparative study of intensive care and general care units. Crit Care Med 25: 1289-1297. [crossref]

18. Senst BL, Achusim LE, Genest RP, Cosentino LA, Ford CC, et al. (2001) Practical approach to determining costs and frequency of adverse drug events in a healthy care network. Am J Health Syst Pharm 58: 1126-1132. [crossref]

19. Cacabelos R (2012) World Guide for Drug Use and Pharmacogenomics. EuroEspes Publishing Co. Corunna, Spain.

20. Cacabelos R (2009) Pharmacogenomic Biomarkers in Neuropsychiatry: The Path to Personalized Medicine in Mental Disorders. In: The Handbook of Neuropsychiatric Biomarkers, Endophenotypes and Genes: Molecular Genetic and Genomic Markers. Ritsner MS (Ed). Springer, Germany: pp 23-63.

21. Cacabelos R, Fernández-Novoa L, Martínez-Bouza R, McKay A, Carril JC, et al (2010) Future trends in the pharmacogenomics of brain disorders and dementia: Influence of APOE and CYP2D6 variants. Pharmaceuticals 3: 3040-3100. [crossref]

22. Cacabelos R, Martínez-Bouza R, Carril JC, Fernández-Novoa L, Lombardi V, et al. (2012) Genomics and pharmacogenomics of brain disorders. Current Pharmaceutical Biotechnology 13: 674-725. [crossref]

23. Cacabelos R (2012) Pharmacogenomics of central nervous system (CNS) drugs. Drug Development Research 73: 461-476.

24. Cacabelos R (2012) The metabolomics paradigm of pharmacogenomics in complex disorders. Metabolomics 2: 5 .

25. Cacabelos R, Cacabelos P, Aliev G (2013) Genomics and pharmacogenomics of antipsychotic drugs. Open J Psychiatry 3: 46-139.

26. Cacabelos R (2015) Impact of genomic medicine on the future of Neuropsychopharmacology. J Neuropsychopharmacol Mental Health 1: 1 .

27. Cacabelos R (2005) Pharmacogenomics and therapeutic prospects in Alzheimer's disease. Expert Opin Pharmacother 6: 1967-1987. [crossref]

28. Cacabelos R (2007) Molecular pathology and pharmacogenomics in Alzheimer's disease: Polygenic-related effects of multifactorial treatments on cognition, anxiety, and depression. Meth Find Exper Clin Pharmacol 29: 1-91. [crossref]

29. Cacabelos R, Cacabelos P, Torrellas C, Tellado I, Carril JC (2014) Pharmacogenomics of Alzheimer's disease: novel therapeutic strategies for drug development. Methods Mol Biol 1175: 323-556. [crossref]

30. Cacabelos R, Carril JC, Cacabelos P, Teijido O, Goldgaber D (2016) Pharmacogenomics of Alzheimer's Disease: Genetic determinants of phenotypic variation and therapeutic outcome. J Genomic Med Pharmacogenomics : 151-209. [crossref]

31. Cacabelos R (2014) Epigenomic networking in drug development: from pathogenic mechanisms to pharmacogenomics. Drug Dev Res 75: 348-365. [crossref]

32. Cacabelos R (2015) Metabolomics of drug resistance in cancer: The Epigenetic Component. Metabolomics 5: 4 .

33. PharmGKB

34. EuroPharmaGenics

\section{Citation:}

Ramon Cacabelos (2017) Misuse of drugs and personalized treatment in geriatric patients. Ageing Sci Ment Health Stud Volume 1(1): 1-2 